\title{
Glutamatergic Control of Striatal Dopamine Release in Normal Rats and 6-OHDA Rats with Intrastriatal Grafts
}

\author{
T. Kondoh ${ }^{1}$ and W.C. Low ${ }^{1,2,3}$ \\ Departments of ${ }^{1}$ Neurosurgery and ${ }^{2}$ Physiology, and ${ }^{3}$ Program in Neuroscience, University of Minnesota \\ Medical School, Minneapolis, MN 55455, USA
}

\begin{abstract}
Recent animal experiments suggest that transplanted neurons become integrated with the host brain. Neuroanatomical studies have shown that transplanted dopaminergic neurons can form synaptic connections on target cells in the host striatum. Other studies also have shown that grafted neurons not only innervate the host striatum but also receive afferent inputs from neurons of the host. However, little is known about the dynamic regulation of graft-derived dopamine (DA) release by the host brain. In normal animals, cortical neuronal input to the striatum is carried mainly via glutamate (Glu) neurons. Interactions between DA and Glu in the striatum are shown by in vivo and in vitro studies. Using in vivo microdialysis, the present study was carried out in order to elucidate the effects of glutamatergic agonists and Glu blockade on DA release in the normal striatum and in the striatum of 6-OHDA rats with dopamine grafts.
\end{abstract}

\section{MATERIAL AND METHODS}

\section{Transplantation}

Fetal nigral dopaminergic cell suspensions ( $\mathrm{E}$ $=14-16$ day, 50,000 cells $/ \mu 1 \times 2 \mu l)$ were implanted into the striatum of rats with complete unilateral 6-OHDA lesions of the nigrostriatal dopaminergic pathway. Rotational behavior induced by amphetamine $(5 \mathrm{mg} / \mathrm{kg}$ i.p.) was studied before surgery and for two months following transplantation. Animals which exhibited an amelioration of rotational asymmetry were used for the microdialysis study.

\section{In vivo microdialysis}

In vivo measurements of $\mathrm{DA}$ release were made using intracerebral microdialysis. Under halothane anesthesia, a microdialysis probe (4 $\mathrm{mm}$ length, $0.5 \mathrm{~mm}$ i.d.) was implanted into the striatum and perfused with artificial CSF at a flow rate of $2.0 \mu \mathrm{l} / \mathrm{min}$. After stabilization of basal DA release, drugs were perfused for ten min and samples were directly injected into the HPLC system with electrochemical detection (BAS 460).

\section{Glutamate agonists and glutamate uptake inhibition}

To study the effects of Glu on DA release, two glutamatergic agonists, kainic acid (KA) and $\mathrm{N}$-methyl-D-aspartate (NMDA), were added to the perfusate for ten min into the normal striatum. The concentrations of each agonist were 1, $10,100 \mu \mathrm{M}$ and $1,10,100,1000 \mu \mathrm{M}$, respectively. Thereafter, we chose KA as a stimulant of DA release. Concentrations of $10 \mu \mathrm{M}$ and 100 $\mu \mathrm{M}$ of $\mathrm{KA}$ were perfused into the transplanted striatum. To study the effects of Glu uptake blockade on striatal DA release, dihydrokainic acid (DHKA; $5 \mathrm{mM}$ ), a glutamate uptake inhibitor, was added to the perfusate in the striatum of normal animals, the contralateral striatum of lesioned animals and in the striatum with dopamine grafts.

\section{RESULTS}

In the normal striatum $1 \mu \mathrm{M}$ of $\mathrm{KA}$ was found to induce DA release. DA release in response to $\mathrm{KA}$ was dose-dependent. NMDA administration 
did not affect dopamine release except at a high concentration of $1000 \mu \mathrm{M}$. In transplanted animals, $10 \mu \mathrm{M}$ of $\mathrm{KA}$ did not evoke DA release. However, $100 \mu \mathrm{M}$ of KA evoked DA release up to 3.3-fold of the basal value. Perfusion of DHKA evoked DA release up to 21 -fold in the normal striatum and 3.5-fold in the transplanted striatum (Figure).

These results indicate that transplanted dopaminergic neurons in the striatum can be stimulated by Glu via the kainic acid receptor and that blockade of endogenous Glu uptake can evoke DA release from the grafted neurons. These results suggest that glutamatergic afferents from the host brain are capable of regulating dopamine release of transplanted mesencephalic neurons.

This work was supported by PHS grant R01-NS24464.
Effect of DHKA $(5 \mathrm{mM})$ on DA

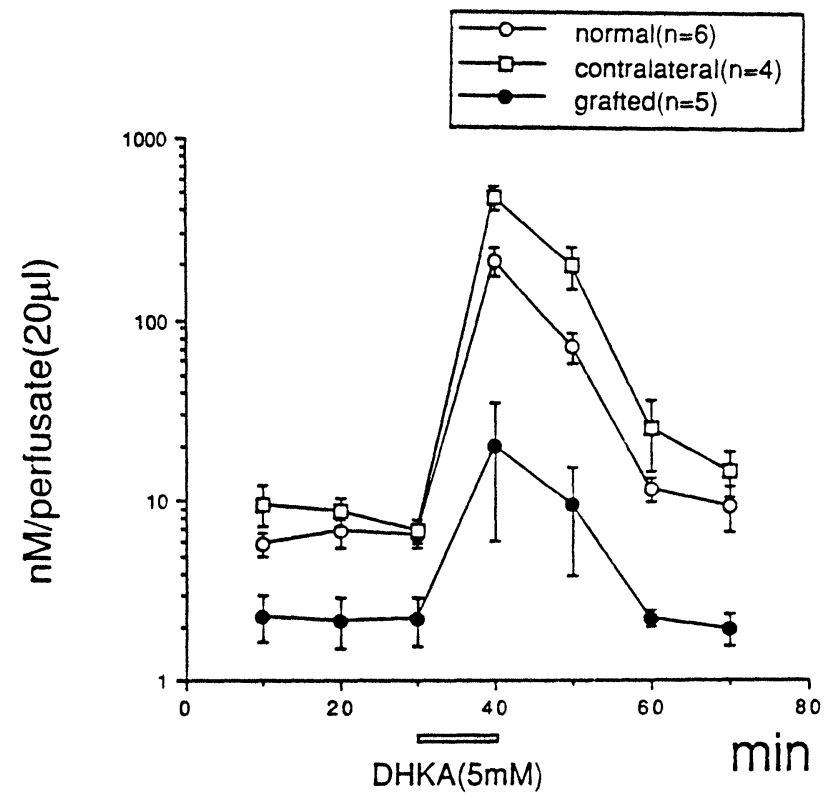



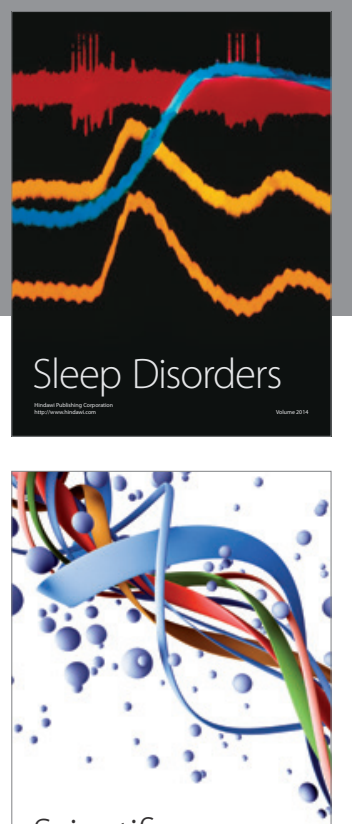

Scientifica
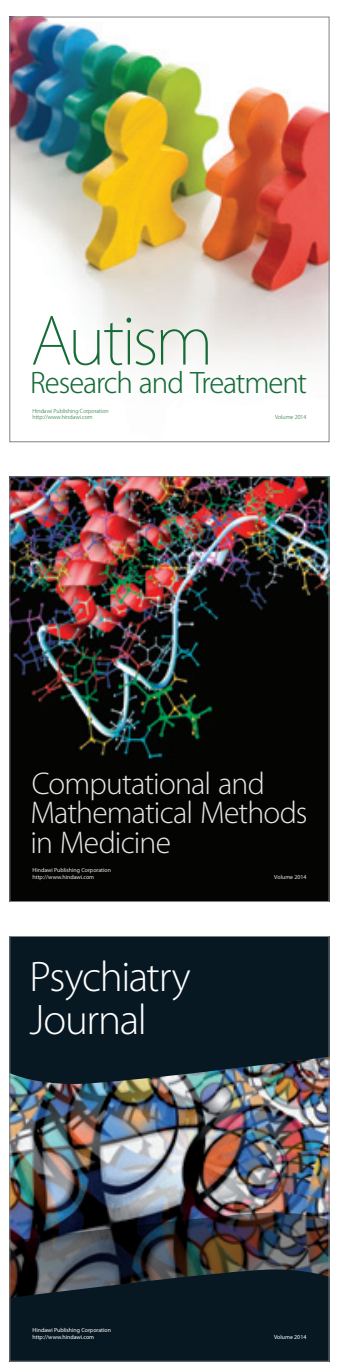
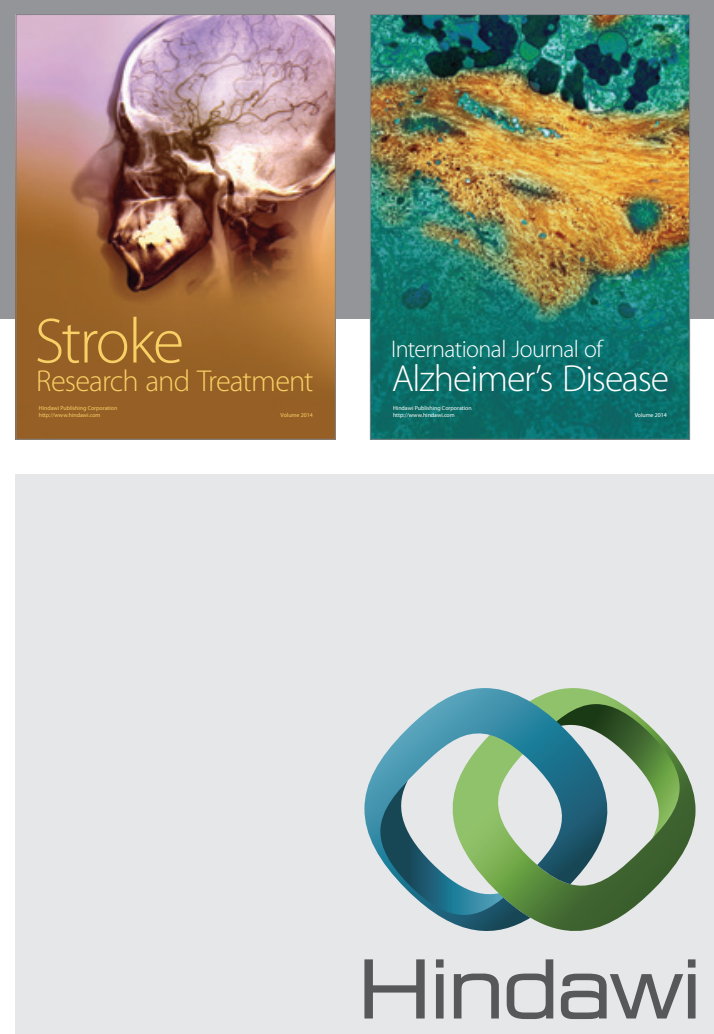

Submit your manuscripts at

http://www.hindawi.com
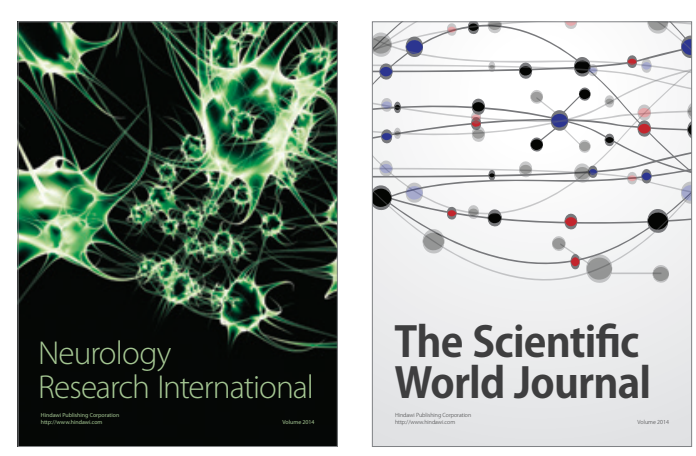

The Scientific World Journal

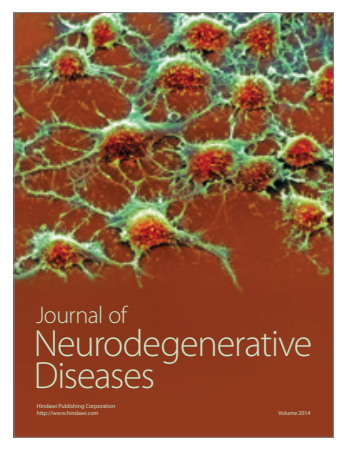

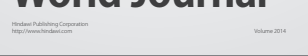

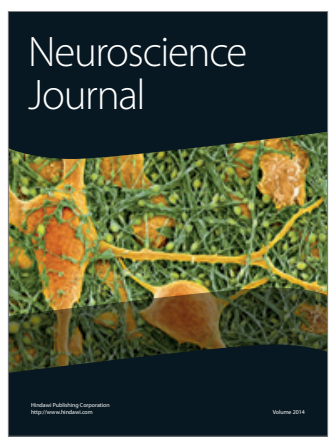

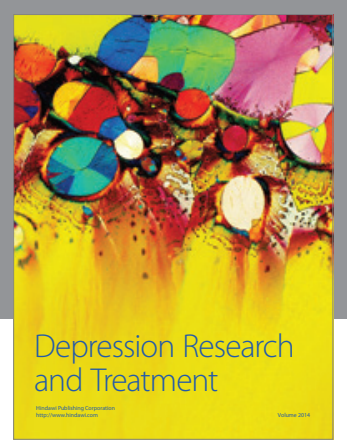
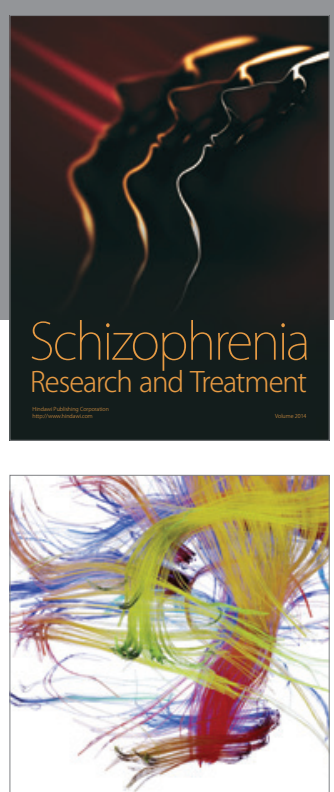

Brain Science

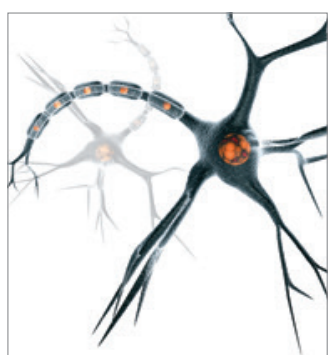

Neural Plasticity
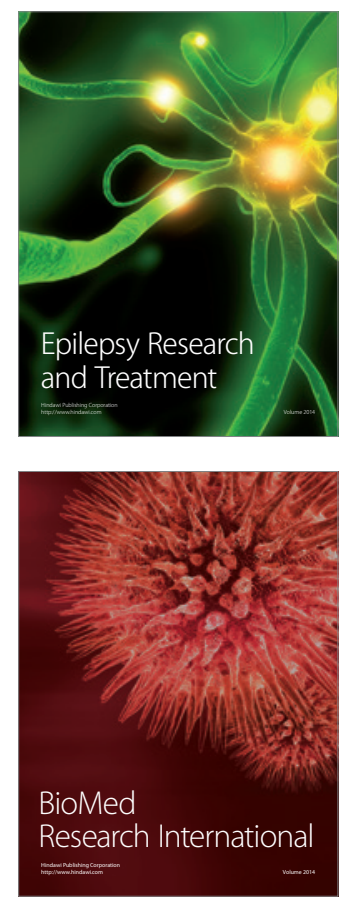

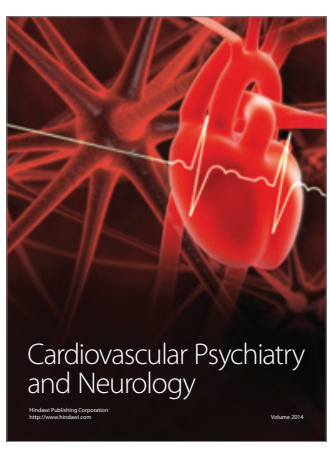

Parkinson's

Disease
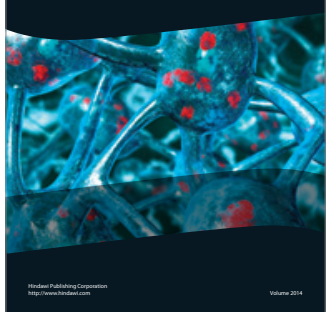